\title{
Reconstrucción Social, a través de la enseñanza-aprendizaje de las artes visuales, en la formación del profesorado
}

\section{Social Reconstruction through the teaching and learning of visual arts in teacher education}

\author{
Luis Claudio Cortés Picazo ${ }^{2}$ \\ Departamento de Artes Plásticas, Facultad de Educación, \\ Universidad Autónoma de Chile, Talca, Chile. \\ lcortesp@uautonoma.cl
}

Recibido: 27 de noviembre de 2010

Aprobado: 8 de febrero de 2011

\begin{abstract}
Resumen
El presente documento evidencia actividades didácticas entorno a la enseñanza-aprendizaje de las artes visuales, insertas en el proceso de formación de profesores especialistas en el área. Para ello, durante el periodo Otoño 2010, se diseñan una serie de actividades centradas en los niveles de enseñanza media, de acuerdo a los objetivos, unidades y contenidos especificados en los Planes y Programas de estudios, del Ministerio Nacional de Educación, de Chile. Tales actividades, además, incrementan las competencias profesionales de docentes especialistas en artes visuales, de la Universidad Autónoma de Chile, con sede en la ciudad de Talca. Para lo cual, se distribuyen consecutivamente cuatro actividades didácticas, centradas en el enfoque de "reconstrucción social", señalado por Sleeter y Grant (1987) y Efland, Freedman y Stuhr (1996)
\end{abstract}

Palabras Clave: Artes Visuales-Formación del Profesorado-Posmodernidad-Reconstrucción Social.

Cortés, L.C. 2011: Reconstrucción Social, a través de la enseñanza-aprendizaje de las artes visuales, en la formación del profesorado. Arte, Individuo y Sociedad, 23 (2), 9-22

\begin{abstract}
This document shows educational activities around the teaching and learning of visual arts, embedded in the process of teacher training specialists in the area. Accordingly, during the period Fall 2010, designed a series of activities focusing two levels of secondary education, according to the objectives and content units specified in the Plans and Programs Study, Ministry of Education. Such activities are to increase the professional skills of future teachers or specialist in visual arts, of the University of Chile, based in the city of Talca. To which are distributed consecutively four teaching units that focus on the approach of "social reconstruction", identified by Sleeter and Grant (1987) and Efland, Freedman and Stuhr (1996)
\end{abstract}

Key Words: Visual arts- Formation of the Professorship- Postmodern era- Social reconstruction.

Cortés, L.C. 2011: Social Reconstruction through the teaching and learning of visual arts in teacher education. Arte, Individuo y Sociedad, 23 (2), 9-22 
Sumario: 1. Planteamiento del problema, 2. Objetivos, 3. Marco Teórico, 3.1 Reconstrucción social, como enfoque posmoderno, 3.2. Arte y posmodernidad en Chile, 4. Metodología, 5. Conclusiones. Referencias

\section{Planteamiento del problema}

La acción docente en la formación del profesorado, implica el uso de estrategias metodológicas conducentes al proceso de enseñanza-aprendizaje, centrado en los y las estudiantes. Los métodos tradicionales, cimentados en la transmisión pasiva de conocimientos, implican acciones no necesariamente del interés de los y las estudiantes. Los métodos activos, en cambio, definen una docencia conducente a la investigación, permitiendo abordar contenidos de interés para estudiantes, docentes y la comunidad educativa en su conjunto. Para ello, se requiere de docentes comprometidos con el proceso, en la medida que asumen el rol de investigadores intermediarios, es decir, articuladores del saber y no dueños de él. Los y las estudiantes, por su parte, construyen el conocimiento, en tanto adoptan el rol de investigadores-participantes. Y la comunidad en su conjunto, comprendida como soporte de diversas manifestaciones culturales y locales, cuyos integrantes son definidos como informantes-claves, en la medida que aportan con información relevante. (Rodríguez, Gil, y García, 1996)

Dicho proceso, conocido como investigación-acción (Elliot, 1997), dista mucho de la formación del profesorado especialista en artes plásticas basada en la disciplinas artísticas e integración de éstas, vislumbrando una docencia activa en teoría, pero, pasiva en la práctica, alejada de intereses comunes. En teoría, la malla curricular de la carrera de Pedagogía y Licenciatura en Artes Plásticas, impartida en la ciudad de Talca, en la universidad Autónoma de $\mathrm{Chile}^{3}$, no garantiza bajo su estructura, en ningún caso la formación docente conducente a la investigación, y por ende, limita la docencia y ejercicio libre de las artes, en la escena local.

A raíz de lo expuesto, se deja entrever una problemática que a través de un plan de mejora, basado en acciones conducente a la investigación, permite replantear metodologías didácticas ejercidas en el proceso de formación del profesorado. Generando reflexión crítica sobre teorías y prácticas de inserción y aproximación pedagógica. Fortaleciendo directamente y de forma estratégica, la articulación de las distintas áreas de formación que estructuran el plan de estudio de dicha carrera: área de formación disciplinar, área de formación general, área de formación profesional y área de formación práctica.

Se plantea, de esta forma, una hipótesis cimentada en un plan de mejora, implementado durante el primer semestre de 2010. Lo que permite en un comienzo, insertar tres asignaturas pilotos: Didáctica de las Artes Visuales I, Didáctica de las Artes Visuales II y Didáctica de las Artes Visuales III. Las cuales, se incorporan el área de formación profesional en el $1^{\circ}, 3^{\circ}$ y $5^{\circ}$ año de la carrera, respectivamente. Generando, de esta forma, una tensión entre el saber disciplinar y la formación práctica de los y las estudiantes. Para tal efecto, se escoge el enfoque de "reconstrucción social", según Grant y Sleeter (1989; 1993), el cual, es abordado específicamente en el $5^{\circ}$ año de la carrera, es decir, en Didáctica de las Artes Visuales III.

El plan de mejora, enmarcado en la teoría crítica, permite la generación de propuestas no tan sólo interdisciplinares, sino además, mecanismos didácticos experi- 
mentales que cuestionan el desarrollo cultural anidado en tradiciones que limitan las transformaciones y apertura social de las artes y la cultura local. Puesto que la ciudad de Talca, al ser ciudad capital de la Región del Maule, asume un rol protagónico en el ámbito cultural, que no ha sido del todo fructífero:

La realidad de la Región del Maule, desde el punto de vista económico, demuestra que la zona ha sabido insertarse en los desafios que demanda la globalización y los procesos de internalización del mercado; sin embargo, la realidad cultural resulta paradojal, reflejada en un estancamiento en su desarrollo. Si bien la Región ha entrado en un proceso de modernización, no se ha asimilado a la modernidad, entendida como una sensibilidad frente a los procesos de desarrollo social y cultural (CNCA, 2005:9).

En el ámbito cultural, la región ha sido definida con una identidad desprovista de una personalidad particular, por un lado lo popular, rural y, por otro, lo producido por el mundo culto, urbano. Marcando una evidente dicotomía entre arte popular y arte culto, del cual subyace una problemática en términos de clase, raza y género.

A raíz de lo planteado, resulta prioritario explicar los hechos de la situación, los cuales a su vez, "aluden a la relación entre los hechos de la situación problemática y otros factores que operan en su contexto" (Elliott, 2000:93), bajo los siguientes términos: "La docencia conducente a la investigación en la formación del profesorado especialista en artes visuales, puede garantizar el proceso de enseñanza-aprendizaje de las artes, centrado en el enfoque de reconstrucción social".

\section{Objetivos}

La problemática y aspectos señalados anteriormente, definen los siguientes objetivos:

- Analizar y comprender la reconstrucción social, como enfoque posmoderno de enseñanza-aprendizaje de las artes visuales, en relación a situaciones contingentes de la realidad local.

- Diseñar y construir propuestas didácticas de las artes visuales insertas en un marco teórico-crítico de enseñanza y aprendizaje de las artes.

- Sensibilizar el desarrollo de la creación artística, mediante temáticas que permitan tomar conciencia, a través, del enfoque de reconstrucción social, de discursos y prácticas artísticas posmodernas desarrolladas en Chile.

\section{Marco Teórico}

\subsection{Reconstrucción social, como enfoque posmoderno}

Grant y Sleeter (Efland,et.al.2003), distinguen cinco enfoques pedagógicos de educación multicultural. El enfoque pedagógico basado en casos especiales, en las relaciones humanas y en el estudio de un grupo singular, asociados a la teoría de la modernidad, mientras el enfoque basado en la educación multicultural y de reconstrucción social, se asocian con la teoría de la posmodernidad. 
El enfoque de reconstrucción social, permite articular un programa artístico oficial en torno al arte tal y como se experimenta en la vida, como parte integrante del contexto social y cultural. Así pues:

....se enseña abriendo canales de comunicación con otras asignaturas escolares, especialmente los estudios sociales. Se incita a los estudiantes a participar en la construcción del currículo, ya sea, aportando sus experiencias personales como explorando diversas formas y obras artísticas que encuentran en sus respectivas casas y comunidades o bien en la región, el país y el mundo en el que viven (Efland,et.al.2003:144)

Los objetivos trazados para una didáctica experimental de las artes visuales, como mecanismo metodológico centrado en la investigación-acción, torna necesario el eficiente y buen desempeño de estudiantes de Pedagogía y Licenciatura en Artes Plásticas, en la medida que articulan el ámbito de formación disciplinar, general, profesional y práctica, de forma integral. De hecho, en la formación práctica, se considera el enfoque de reconstrucción social bajo cuatro principios prácticos, según Grant y Sleeter:

1. La democracia debe ser ejercida activamente en la institución educativa.

2. Los y las estudiantes aprenden a analizar sus propias situaciones.

3. Los y las estudiantes adquieren instrumentos de accion social, que les ayudan a ejercer la democracia y analizar sus propias situaciones.

4. Se instruye a estudiantes y grupos sociales acerca de cómo aliarse y trabajar juntos más allá de las fronteras de raza, género, clase social y minusvalía (Efland,et.al.2003)

La reconstrucción social, como enfoque de la educación de las artes, pretende en definitiva que los pequeños relatos o microrrelatos, como soportes de representación de grupos marginales y/o minoritarios, sean considerados contenidos suceptibles de ser abordados didácticamente al interior del aula. Contribuyendo a una ciudadanía informada, cuestionadora de la autoridad y del statu quo, aceptando las diferencias y actuando en defensa de los demás y del entorno.

\subsection{Arte y posmodernidad en Chile}

La reconstrucción social bajo su vertiente posmoderna en Chile, encuentra sus raices a partir de 1973, es decir, en plena dictadura militar. Los y las artistas posmodernos, manifiestan gran apertura hacia los recursos culturales de épocas pasadas, apropiándose de ciertos motivos para ser integrados en sus trabajos. Pronunciándose seria y profundamente sobre las complejidades del mundo contemporáneo, interesándose a menudo por la superficie, la yuxtaposición y la ilusión, sugiriendo conceptos contradictorios. De hecho, más que un estilo definido, los artistas posmodernos funda el eclecticismo.

Jenks en 1987, menciona que la posmodernidad en las artes, comprende las siguientes características: 
Los artistas posmodernos tienden a usar una belleza disonante o una armonía inarmónica, rechazando las ideas modernas sobre composición. Reinterpretan la tradición. El estilo posmoderno es ecléctico, reflejo de la pluralidad de las fuentes culturales y políticas de origen de la obra...Los soportes son diversos, hacen uso de objetos e imágenes variadas, reciclándolas y re-contextualizándolas mediante instalaciones o a través del uso de nuevas tecnologías de la información e informática. (Efland,et. al.2003: 65-66)

La fundación del Instituto de Investigación Social de Frankfurt, en 1923, genera una serie de reflexiones teóricas y críticas entorno al consumo masivo de productos pseudoculturales en el mundo occidental. Morin y Adorno, al respecto, asientan un precedente al criticar los mecanismos de la industria cultural centrada en la homogeneización, consumo máximo, estandarización y racionalización (Morin y Adorno, 1967). En Chile, Adriana Valdés, señala que la teoría crítica entorno a las artes visuales en Chile, es sintomática, ya que es y ha sido un "síntoma de Chile": "Se ha dicho ya que después del golpe militar el salto teórico que dio la crítica fue de tal magnitud que puede describirse como un verdadero trauma cultural, cuyas huellas se reconocen hasta hoy" (Mosquera,2006:46)

Las variables posmodernas de las artes, centradas en la producción de obras enmarcadas en la teoría crítica, cuestionan los postulados modernos de las artes en occidente. En Chile, Milán Ivelic y Gaspar Galaz (1988) revisan cronológicamente la producción de las artes en el siglo XX, las que transcurren desde la semiótica del objeto, abarcando la instalación y el performance, junto al uso del cuerpo como objeto y la acción artística marginada de la escena institucional, en plena dictadura militar. $\mathrm{Al}$ respecto, destacan cuatro etapas que delimitan dicho proceso:

1. El uso del objeto en la obra.

2. La instalación como escenografía de múltiples objetos.

3. El cuerpo como objeto en acción o performance.

4. La interdisciplinareidad.

A partir de 1965, la primera etapa contempla la vinculación con el Pop-Art y Arte Povera, teniendo como figura local a Francisco Brugnoli, quien emplea objetos de desechos y desperdicios, descontextualizados y desprovistos de su significado habitual para ser resemantizados. Esto se debe principalmente a que Brugnoli excluye cualquier intento formal destinado a maquillar el significante, así como, también hacerlo atractivo. Marcando un quiebre con la institucionalidad de la academia tras una reflexión crítica ante la mercantilización de la obra. Por ello, el uso de los denominados "pegoteados", obedece a una crítica dirigida a los signos de la pobreza, junto a los significados de la cesantía e inequidad social del contexto latinoamericano (Ivelic y Galaz,1988:160). 


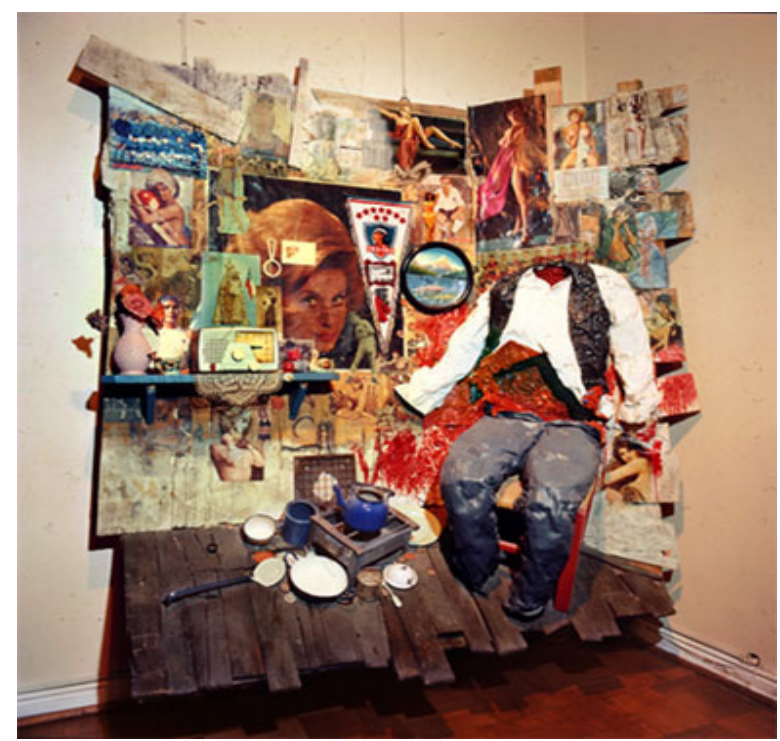

Fig. 1. Francisco Brugnoli, Reportaje (1966)

Desde mediados de los setenta, surge lo efímero como negación de la comercialización de la obra. Lo efímero se convierte en principio ideológico, es decir, la obra surge y no alcanza a generar una vida propia, desapareciendo tras su génesis; reafirmándose el rechazo ante cualquier necesidad de posesión y comercialización. Esta orientación conceptual, significó el desplazamiento del objeto por la idea, tomando fuerza el arte como operación mental, privilegiando su función en el contexto, no así su morfología, desinteresándose de las apariencias. La "instalación”, en este sentido, configura la segunda etapa, por lo que Virginia Errázuriz selecciona rigurosa y analíticamente los materiales cuya precariedad y economía, originan su obra "Paisaje" de 1984. Sus obras antes de ser expuestas, tras previos intentos efímeros de puesta en escena, son registradas y documentadas fotográficamente, lo que permite optar por una instalación definitiva. Así, "registrar y conservar, de manera testimonial, la desaparición de un grupo de conciudadanos", constituyó el sustento teórico de elección de muchos de sus materiales y recursos técnicos. Catalina Parra por su parte, aborda la contingencia política del país con su instalación "Imbunches" en 1977. Término de origen mitológico y mapuche, cuyo significado narra la transformación del hijo de una madre cristiana raptado por brujos y convertido tras un macabro proceso, en imbunche. Dicho proceso, implica borrar el sacramento del bautismo mediante baños de caída de agua, con el objeto de ser dieta especial y protección para los brujos, quienes someten a este hijo mediante una transformación física, zurciéndole todos los orificios de su cuerpo: boca, ojos, oídos, nariz y ano. Se le quiebra una de sus piernas, la cual es zurcida a su espalda de tal forma que se sostenga en tres extremidades, se le corta la lengua longitudinalmente, convirtiéndose en instrumento del mal. De esta forma, Catalina Parra revive el mito para proyectarlo en una realidad desgarrada y remedada precariamente (Ivelic y Galaz,1988:181-183). 


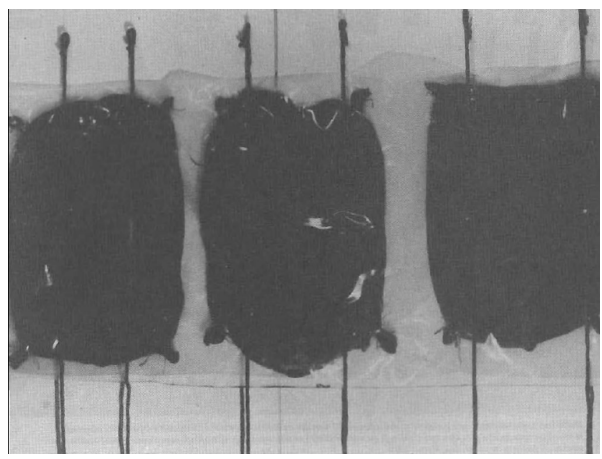

Fig. 2. Catalina Parra, Imbunches (1977)

La tercera etapa, enmarcada por el uso del cuerpo como soporte de la experiencia artística, se ve influenciada por el "performance". Marcela Serrano en 1979, Elías Adasme en 1980 y Carlos Leppe a partir de 1974, hasta comienzos de los ochenta, configuran un tratamiento de esta tendencia en base a la reflexión crítica de la antropología del cuerpo y su cosificación como signo lingüístico portador de un significado y significante. El cuerpo cuyo contenido mágico-mítico de sociedades llamadas primitivas, es trasladado al acontecer político local, en tanto objeto de intervención, pero esta vez, violentado en el cuerpo del artista. Por ejemplo, Carlos Leppe y su obra el "Perchero" de 1975, expone un cuerpo-objeto frente al cuerpo-social. El cuerpo del artista transcurre entre lo íntimo y lo privado de su experiencia corporal, ocultando su ser del ámbito público y social, exhibiendo su cuerpo, como signo, en circuitos artísticos no oficiales. Exhibe su cuerpo en espacios periféricos a la institucionalidad del arte en Chile, es decir, ocultando su cuerpo a los ojos público. Dicha experiencia del cuerpo como soporte de la obra, subyace de la crítica dirigida a la cosificación de la obra como objeto comercializable. Empleando en su lugar mecanismos de reproducción como la fotografía, el video y el cine, dando cuenta, no directa sino testimonialmente, de un hecho o performance irrepetible que es imposible de ser reproducido de igual forma.

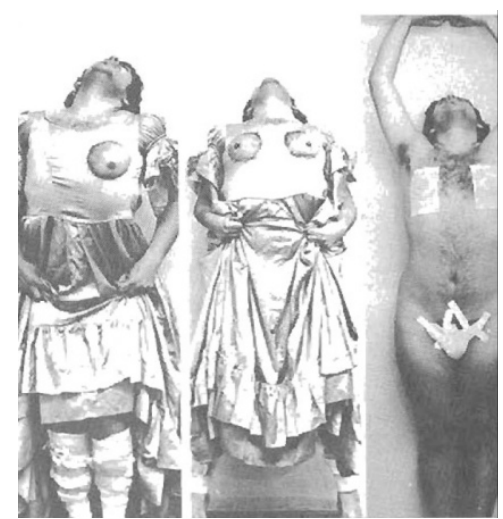

Fig. 3. Carlos Leppe, El perchero (1975) 
A partir de aquí, el uso de la fotografía, el cine y el video, se instalan como soportes de experiencias artístico experimentales. La vinculación arte/vida y arte/política, se transforman en el nuevo marco teórico que sustenta la relación transgresora entre las fronteras a fines de los setenta. Cruzan las fronteras los géneros de las artes visuales, literatura, poesía, video, cine, texto crítico, la performance e intervención urbana. La ciudad o el espacio público, como soporte de la acción y el cuerpo como objeto efímero de transformación; analiza y reflexiona críticamente sobre los espacios y lugares intervenidos violentamente por la dictadura. Panorama en el que surge la "Escena de Avanzada", como cuarta etapa. Sus integrantes, provenientes de diversas disciplinas, plantean la vinculación entre arte y política, irrumpiendo los códigos unificadores de la izquierda opositora al régimen dictatorial. La "Escena de Avanzada" reconceptualiza el nexo entre arte y política fuera del ámbito ideológico de la izquierda ortodoxa:

Destacar lo precursor de un trabajo con el arte y sobre el arte que participaba del ánimo vanguardista de experimentación formal y de politización de lo estético. Tomar distancia con la epopeya modernista de la Vanguardia que internacionalizaban las historias del arte metropolitanas destacando la especificidad local de una escena de emergencia (Mosquera,2006:109)

Uno de los colectivos de arte protagonista de la escena, fue C.A.D.A., o Colectivo de Acciones de Arte, conformado por Fernando Balcell, sociólogo; Juan Castillo, artista plástico; Diamela Eltit, escritora; Lotty Rosenfeld, artista visual y Raúl Zurita, poeta. A partir de 1979, omiten en cada acción de arte, los nombres propios, por ser el resultado de un trabajo colectivo e interdisciplinario, entrecruzándose texto escrito, fotografías y videos.

Lotty Rosenfeld, en primer lugar, sobre la panamericana en pleno desierto chileno (1979) y posteriormente frente a la Casa Blanca en Washington (1981), emplea el video como mecanismo de registro de la intervención; irrumpiendo y transgrediendo la funcionalidad del signo que separa las dos vías de circulación de la carretera, despojándole de su significado habitual, transformándolo en signo aritmético o religioso. Según Lotty Rosenfeld. (Foxley 1981), las acciones de arte constituyen una experiencia que invita a la sociedad chilena a subjetivizar el acontecer político: "El panorama de la subversión y revolución de la experiencia artística local se tradujo en el entendimiento desgarrado con el presente (CADA,1982:2)

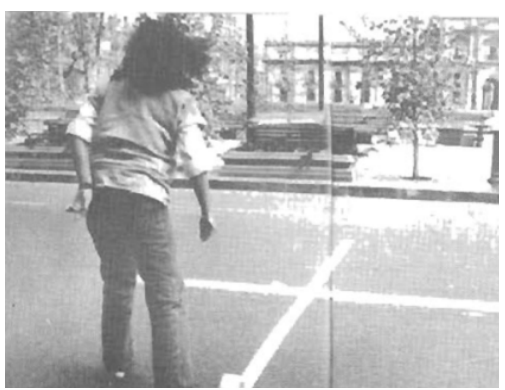

Fig.4. Lotty Rosenfeld, Una milla de cruces sobre el pavimento (1979) 


\section{Metodología}

El movimiento de Investigación-Acción educativa surgió tras la oposición al desarrollo tecnológico del currículum, el cual insistía, sobre todo en el Reino Unido, en la especificación antecedente de resultados mensurables de aprendizaje. (Elliott,2000: 69). Fenómeno del cual no escapa la Reforma Educacional en Chile tras el regreso de la democracia, por cuanto la mejora y cambio, estuvo prescrita en términos de innovación enfatizada en la centralización, jerarquización y desarrollo tecnocrático del quehacer docente.

Por ello, una de las razones fundamentales del porqué la Investigación-Acción fue elegida para el presente plan de mejora, responde a uno de los requerimientos fundamentales en cuanto hace alusión a la formación de profesores como investigadores. Supone la transformación de la cultura profesional por una cultura reflexiva, colaborativa y cooperativa, en base a cuestiones comunes, no individuales ni tecnócratas. De hecho, la Investigación-Acción se desarrolla en el seno de un movimiento internacional de redes cooperativas de profesores formadores e investigadores educativos, para el desarrollo profesional de los docentes. Por tal motivo, la InvestigaciónAcción, se adopta como metodología de investigación cualitativa, en la medida que sus pasos quedan definidos por ciclos. (Elliott,1997,2000)

Para el presente plan de mejora se define un primer ciclo, que permite implementar la Didáctica de las Artes Visuales III, desde una perspectiva crítica, por cuanto, se enmarca en el enfoque de reconstrucción social anidado en la posmodernidad.

I. Ciclo $1^{\circ}$ : Abril-Junio de 2010

II. Identificación de la idea inicial

La formación del profesorado especialista en artes visuales, en la carrera de Pedagogía y Licenciatura en Artes Plásticas, en la Universidad Autonóma de Chile, ubicada en al ciudad de Talca, Chile, enfatiza principalmente una formación disciplinar y tradicional. Para lo cual, se implementa un plan de mejora, desde el área de formación profesional, en el $5^{\circ}$ año de la carrera, mediante la inserción de la Didáctica de las Artes Visuales III, enfocada desde la reconstrucción social, como mecanismo de acción social y cuestionamiento al status quo local.

De lo cual subyace la siguiente pregunta: ¿El contexto de la cultura local, a nivel regional, esta en condiciones de asimilar activamente el desempeño y ejercicio de creación artística de estudiantes de dicha carrera, desde una perspectiva crítica?

\section{Reconocimiento y revisión de idea}

1. Descripción de los hechos de la situación

- Formación disciplinar, en dibujo, pintura, grabado y escultura.

- Malla curricular, inserta dentro de los delineamientos y modelo pedagógico de la Facultad de Educación.

- Escaso conocimiento del origen de la teoría crítica en las artes visuales y por ende, sobre los inicios y desarrollo de las artes experimentales en Chile, 
desarrolladas desde una perspectiva crítica en oposición al contexto local de represión política y cultural de la dictadura militar.

- Énfasis en metodologías didácticas que reproducen el status quo local, mediante el tratamiento plástico de iconografías y simbolizaciones propias de una raza, clase y género, en oposición a enfoques con afán de reconstrucción de la cultura y sociedad en su conjunto.

- Limitada apertura hacia la experimentación de las artes visuales y sesgado uso de las Nuevas Tecnologías de la Información y las Comunicaciones (TIC's)

2. Explicación de los hechos de la situación

"La docencia conducente a la investigación en la formación del profesorado especialista en artes visuales, puede garantizar el proceso de enseñanza-aprendizaje de las artes, centrado en el enfoque de reconstrucción social"

\section{Estructura del plan general}

\section{Enunciado de la idea inicial}

Inserción de contenidos claves de las artes visuales en Chile, para su análisis, discusión y creación de propuestas artístico-experimentales, en base a cuatro etapas de tranformación de las artes, antes y durante la dictadura militar:

- El uso del objeto

- La instalación

- La performance

- La acción de arte.

\section{Enunciado del factor que deseamos cambiar}

Articulación del plan de mejora, con los planes y programas del MINEDUC ${ }^{4}$, en el subsector de artes visuales, para los dos últimos niveles de educación secundaria: NM3 y NM4. Para ello, se insertan cuatro actividades correlativas con las cuatro etapas de transformación de las artes visuales, en Chile, durante la dictadura militar. De lo cual, se deduce un evidente contraste entre enfoques, puesto que mientras el MINEDUC, enfatiza sugerencias didácticas con claro enfoque moderno, el plan de mejora, articula la didáctica desde un enfoque posmoderno, en la medida que se anida en la reconstrucción social. Enfatizando la producción, participación y apertura al debate, tras la realización de propuestas artístico-experimentales.

Para ello se diseña el siguiente recuadro, que permite relacionar la estructura curricular oficial, las respectivas actividades y la correspondiente producción artística, generadas a partir de la aplicación del plan de mejora: 


\begin{tabular}{|c|c|c|c|c|}
\hline Niveles & Objetivos Fundamentales & Unidades & Contenidos & Actividades \\
\hline $\begin{array}{l}3^{\circ} \mathrm{AÑO} \\
\text { MEDIO }\end{array}$ & $\begin{array}{l}\text { Valorar aspectos estéticos, } \\
\text { sociales y funcionales en el } \\
\text { diseño de objetos de la vida } \\
\text { cotidiana }\end{array}$ & $\begin{array}{l}\text { Reconociendo el } \\
\text { diseño en la vida } \\
\text { cotidiana }\end{array}$ & $\begin{array}{l}\text { Objetos de la } \\
\text { vida cotidiana }\end{array}$ & $\begin{array}{l}\text { El uso del objeto: } \\
\text { Pop-Art }\end{array}$ \\
\hline $\begin{array}{l}3^{\circ} \mathrm{AÑO} \\
\mathrm{MEDIO}\end{array}$ & $\begin{array}{l}\text { Expresar ideas, emociones y } \\
\text { sentimientos, a partir de formas } \\
\text { percibidas en la observación } \\
\text { sensible del entorno cotidiano, } \\
\text { evaluando los trabajos realizados } \\
\text { en función de sus características } \\
\text { visuales, expresivas, creativas, } \\
\text { técnicas y por la capacidad de } \\
\text { perseverar en los procesos de } \\
\text { investigación }\end{array}$ & $\begin{array}{l}\text { Aprendiendo a } \\
\text { ver y recrear la } \\
\text { arquitectura }\end{array}$ & $\begin{array}{l}\text { Experiencia } \\
\text { estética del } \\
\text { entorno } \\
\text { arquitectónico }\end{array}$ & $\begin{array}{l}\text { La instalación: } \\
\text { Vivienda Digna }\end{array}$ \\
\hline $\begin{array}{l}4^{\circ} \mathrm{AÑO} \\
\mathrm{MEDIO}\end{array}$ & $\begin{array}{l}\text { Explorar técnicas específicas } \\
\text { de los lenguajes audiovisuales, } \\
\text { reflexionar críticamente respecto } \\
\text { de la dimensión estética y los } \\
\text { contenidos de producciones } \\
\text { audiovisuales y de la televisión }\end{array}$ & $\begin{array}{l}\text { Explorando } \\
\text { lenguajes } \\
\text { artísticos de } \\
\text { nuestra época }\end{array}$ & $\begin{array}{l}\text { Lenguajes } \\
\text { mecánicos y } \\
\text { electrónicos } \\
\text { (Fotografía, } \\
\text { Cine, Vídeo, } \\
\text { Multimedios } \\
\text { interactivos) }\end{array}$ & $\begin{array}{l}\text { La performance: } \\
\text { Fluxus }\end{array}$ \\
\hline $\begin{array}{l}4^{\circ} \mathrm{AÑO} \\
\text { MEDIO }\end{array}$ & $\begin{array}{l}\text { Percibir, experimentar y } \\
\text { expresarse con imágenes } \\
\text { visuales, por medio de, } \\
\text { por ejemplo, la gráfica, la } \\
\text { fotografía, el vídeo, sistemas } \\
\text { computacionales, etc }\end{array}$ & $\begin{array}{l}\text { Conociendo } \\
\text { artistas visuales } \\
\text { contemporáneos } \\
\text { y recreando sus } \\
\text { obras }\end{array}$ & $\begin{array}{l}\text { Artistas del } \\
\text { siglo XX }\end{array}$ & $\begin{array}{l}\text { La acción de arte: } \\
\text { C.A.D.A }\end{array}$ \\
\hline
\end{tabular}


Producción artística:

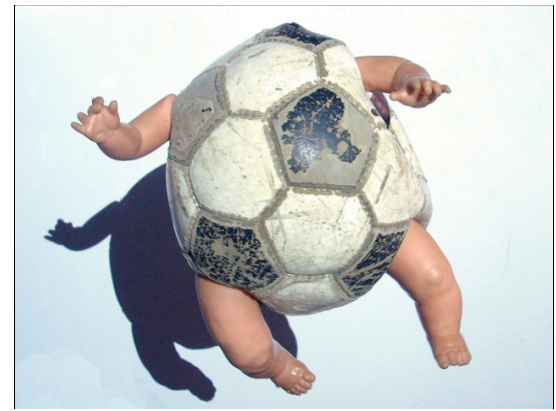

Fig.5. Uso del Objeto"niño pelota"

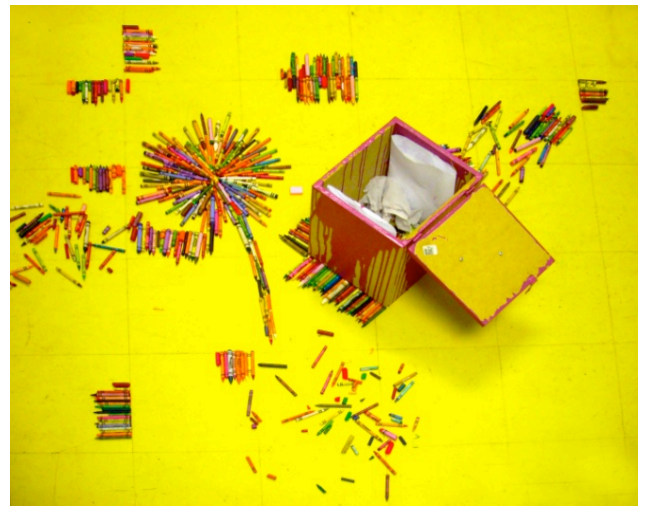

Fig. 7.Performance, “Caja de Ceras"(02’30")

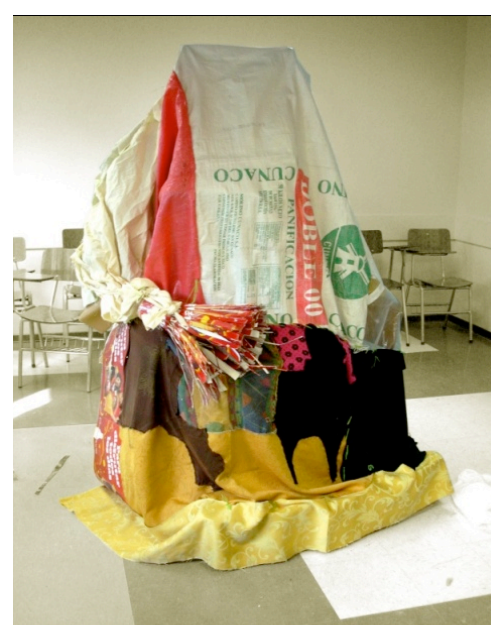

Fig. 6. Instalación "vivienda básica"

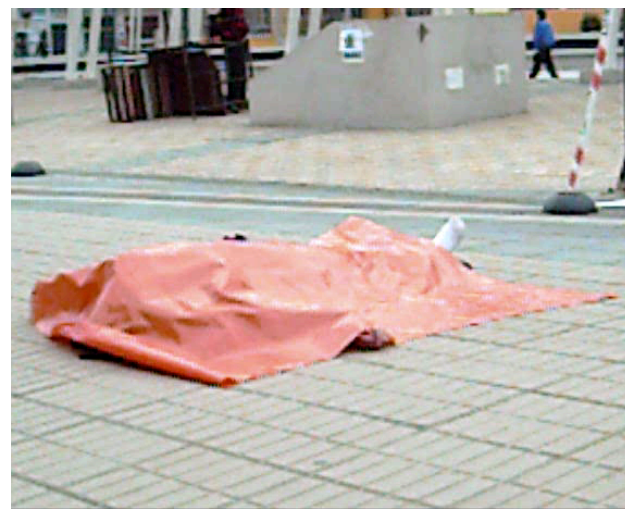

Fig.8.Acción de Arte,"EL Muerto"17 de Julio de 2010, ciudad de Talca, 1 Sur entre 3 y 4 Oriente ( 03 '02")

\section{Conclusiones}

Tras la recogida de datos, por parte del docente, como investigador intermediario y responsable de secuenciar las actividades propuestas, los y las estudiantes como investigadores participantes, articulan los delineamientos estructurales de los planes y programas del MINEDUC, con las cuatro etapas de las artes visuales en Chile. Tales actividades, abren la posibilidad de experimentación, mediante el uso las nuevas tecnologías de la información y las comunicaciones. Sin embargo, la presencia de los informantes-claves, tan sólo pudo evidenciarse en la cuarta actividad, en donde la intervención y acción artística permitió analizarlos en su dimensión cotidiana, sujeta a interpelación, ante la acción de arte titulada "El muerto". 
De esta forma, la disonancia, el collage y yuxtaposicion de significados, mediante la resemantización de objetos descontextualizados de su dinámica de consumo, se inserta en el marco teórico de la posmodernidad. De igual forma, la colaboración conjunta en el diseño, construcción e instalación de una "Vivienda Digna", anulan la autoria del sujeto artista, como único creador, fragmentando la experiencia cotidiana, al invitar a los y las estudiantes a reflexionar sobre las condiciones de habitabilidad de una clase social, en condiciones económicas y culturales específicas de la regíon. La performance, por su parte, permite insoslayablemente el uso de las TIC's, puesto que, una acción, en un espacio específico, en un momento determinado, carece de posibilidad de reproducción, sino es registrada audiovisualmente. De igual forma, la participación de una cierta cantidad de sujetos de la comunidad local, en un momento determinado de sus vidas, es puesta en entredicho en plena vía pública, al interpelarlos ante la imagen de la muerte.

El análisis y comprensión, por lo tanto, de la reconstrucción social, como enfoque posmoderno de enseñanza-aprendizaje de las artes visuales, en relación a situaciones contingentes de la realidad local, se hace efectiva al asumir los roles definidos por la investigación-acción, empleando mecanismo digitales de registros de las experiencias al interior y fuera del aula. Se logra diseñar y construir, además, una serie de propuestas didácticas de las artes visuales insertas en un marco teórico-crítico de enseñanza y aprendizaje de las artes, al cuestionar la defensa del statud quo local, asentadas en la formación disciplinar de los talleres de pintura, grabado y escultura. Por último, los y las estudiantes, conocen y aplican las dinámicas de producción de obras posmodernas desarrolladas en Chile, mediante su inserción como contenido y actividades sugerentes para planificaciones de clases destinadas a $3^{\circ}$ y $4^{\circ}$ año medio de educación secundaria.

Sin embargo, la apuesta de cambio y mejora de un plan de estudios y reestructuración de una malla, no tan sólo requieren de modificaciones en su forma, sino además, en su contenido. Puesto que, no tan sólo la reconstrucción social como enfoque posmoderno de las artes, se abren camino a experiencias anidadas en la generación de conocimiento a partir del debate, sino además, de aquellos enfoques silenciados por sus implicaciones sociológicas que evidencian conflictos de intereses.

Con todo, reconstruir la cotidianeidad a partir de objetos encontrados, abren la reflexión sobre la precariedad de los productos culturales destinados al consumo masivo, sometiéndolos a instancias de reflexión crítica a la luz de experiencias anidadas en el mundo tardomoderno. Cuestionan la pasividad y egocéntrica necesidad de autoria unipersonal de obras inmersas en el circuito cultural para su consumo, mediante el diseño e instalación de estructuras que dialogan con el acontencer mediático de una zona en reconstrucción social y cultural. Debate sobre la experiencia del sujeto, como portador de objetos, sobre los cuales no tan sólo vierte una experiencia, sino además, le construyen como tal, en tanto ser humano definido en términos de clase, genéro y raza. Y por último, reconstruyen desde la marginalidad la experiencia del ser humano inmerso en el espacio público, al irrumpir su individualidad mediante la identificación con lo otro, en la medida que la alteridad social y cultural de los marginados reflejan el latente status quo local. 


\section{Referencias}

C.A.D.A. (1982). Ruptura: Documento de arte. Santiago de Chile: Ediciones C.A.D.A.

Consejo Nacional de la Cultura y de las Artes. (2005). El Muale quiere más cultura. Definiciones de Politica Cultural Región del Maule 2005-2010. CNCA: Gobierno de Chile.

Efland, A. Freedman, K. y Stuhr, P. (2003). La educación en el arte posmoderno. Barcelona: Paidós.

Elliott, J. (1997). La investigación-acción en educación. Madrid: Morata.

Elliott, J. (2000). El cambio educativo desde la investigación-acción. Madrid: Morata.

Foxley, A. (1981). Un Maná Artístico. Revista “Hoy”. 22 al 28 de Julio de 1981. Santiago de Chile.

Ivelic, M. y Galaz, G. (1988). Chile arte actual. Valparaíso: Ediciones universitarias de Valparaíso y Universidad Católica de Valparaíso.

Morin, E. y Adorno, T. (1967). La industria cultural. Buenos Aires: Galerna

Mosquera, G. (2006) Copiar el edén. Arte reciente en Chile. Santiago de Chile: Puro Chile.

Richard, N. (1987). Arte en Chile 1973. Escena de Avanzada y Sociedad. Santiago de Chile: FLACSO, ${ }^{\circ} 46$.

Rodríguez, G., Gil, J., y García, E. (1996). Metodología de la investigación cualitativa. Granada: Aljibe.

\section{Notas}

1. Estudio desarrollado dentro del marco del plan de mejora 2010, de la Carrera de Pedagogía y Licenciatura en Artes Plásticas de la Universidad Autonoma de Chile, sede Talca.

2. D.E.A y Doctor (C) en Educación Artística, Universidad Complutense de Madrid, España. Docente programa de Magister en Humanidades de la Universidad de Talca y programa de formación del profesorado en artes plásticas en la Universidad Autonoma de Chile. (lcortesp@ uautonoma.cl)

3. Institucion privada de educación superior, cuya Carrera de Pedagogía y Licenciatura en Artes Plásticas, ha sido acreditada por 4 años (2010-2014), por la CNA o Consejo Nacional de Acreditación. El informe emitido, tras el proceso de acreditación, solicita estructurar la malla curricular en el área de formación profesional y práctica. Ver informe: http:/www. acreditaccion.cl/Dictamen_..\%5B60\%5D.pdf

4. Ministerio de Educación: http://www.curriculum-mineduc.cl/ 